\title{
ANALISIS PEMASARAN BENIH LELE DUMBO (Clarias gariepinus) Studi Kasus di Desa Parigi Mekar Kecamatan Ciseeng Kabupaten Bogor Jawa Barat
}

\author{
Oleh \\ S u r a t m a n \\ Staff Pengajar Jurusan Penyuluhan Perikanan Sekolah Tinggi Perikanan
}

\begin{abstract}
ABSTRAK
Ikan lele dumbo salah satu komoditas perikanan air tawar yang tergolong ekonomis penting, keadaan ini disebabkan oleh meningkatnya permintaan konsumen akan ikan lele konsumsi. Adapun tujuan penelitian ini adalah ingin mengetahui saluran pemasaran benih ikan lele dumbo dari produsen ke konsumen, menganalisis marjin pemasaran setiap lembaga perantara yang terlibat dan menilai efisiensi pemasaran yang dikaitkan dengan perubahan harga dan penyebaran marjin setiap lembaga perantara. Desa Parigi Mekar mempunyai potensi yang tinggi untuk pengembangan budidaya ikan lele dumbo (khusus sekuen pembenihan), mengingat lahan yang belum dimanfaatkan secara optimal, serta teknik budidya yang masih tradisional/ turun temurun.

Mata rantai pemasaran benih lele dumbo yang dilakukan oleh pembudidaya di lokasi penelitian terdiri dari dua (2) mata rantai pemasaran yaitu:

1. Produsen $----\rightarrow$ Pedagang pengumpul desa $---\rightarrow$ Pedagang pengumpul Kecamatan $--\rightarrow$

Pedagang pengecer --- $\rightarrow$ Konsumen.

2. Produsen $----\rightarrow$ Pedagang pengumpul Kecamatan $--\rightarrow$ Pedagang pengecer $---\rightarrow$ Konsumen.

Masing-masing lembaga perantara tersebut melakukan kegiatan dan fungsi pemasaran yang sama yaitu; a). fungsi pertukaran , b). fungsi fisik dan c) fungsi fasilitas. Perhitungan marjin pemasaran setiap lembaga perantara pada setiap mata rantai pemasaran relative sama. Marjin pemasaran pada mata rantai pemasaran satu (1) sebesar Rp 55,-/ekor atau $44 \%$, begitu pula pada mata rantai pemasaran dua(2) sebesar Rp 55,-/ ekor atau $44 \%$, besarnya biaya pada mata rantai pemasaran satu (1) Rp 15,-/ekor atau 12 \%, sedangkan pada mata rantai pemasaran dua (2) sebesar Rp 12.5,-/ekor atau 10 \%. Keuntungan yang diperoleh pada mata rantai satu (1) sebesar Rp.40,/ekor atau 32. \%, mata rantai pemasaran dua (2) Rp 42.5,-/ekor atau 34 \%.
\end{abstract}

Kata kunci : ikan lele dumbo. Rantai pemasaran. Marjin Pemasaran. Pembudidaya 


\section{PENDAHULUAN}

Secara potensial ikan lele dumbo merupakan ikan yang mempunyai nilai ekonomis yang dapat dijadikan komoditi unggulan di sector perikanan air tawar dengan pertimbangan sebagai berikut;

a). mempunyai daya ketahanan hidup yang tinggi.

b). dapat hidup di air tergenang sekalipun kotor/pemanfaat air limbah rumah tangga.

c). pada kadar oksigen rendahpun dapat tumbuh optimsl.

d). mudah dan relative murah dalam penyiapan pakan.

e). menguntungkan bagi pembudidaya karena harga benih bersaing

f). mempunyai psar yang cukup luas

Panjangnya saluran pemasaran dan banyaknya perantara, menyebabkan rendahnya efisiensi pemasaran dan marjin pemasaran antara pembudidaya selaku produsen dan konsumen menjadi tinggi. Hal ini antara lain disebabkan kurangnya pengetahuan pembudidaya mengenai system pemasaran benih ikan dan informsi pasar. Pola pemasaran yang disarankan yaitu menciptakan pasar yang baru, dekat dengan konsumen akhir, mutu ikan prima, harga eceran bersaing dan harga produsen wajar/ marjin pemasaran relative rendah.
Rumusan Masalah

Dari situasi tersebut, maka muncul pertanyaan-pertanyaan sebagai berikut;

1. Bagaimana rantai tataniaga (pemasaran) yang berlaku di desa Parigi mekar?

2. Bagaimana pola pemasaran diantara lembaga perantara yang terlibat serta fungsi apa saja yang dilakukan oleh lembaga perantara tersebut?

3. Bagaimana efisiensi mata rantai tataniaga dikaitkan dengan perbedaan harga yang diterima produsen dengan harga yang dibayarkan oleh konsumen akhir dan bagaimana penyebaran marjin tataniaganya.

Tujuan Penelitian

1. Mengetahui rantai tataniaga (pemasaran) benih ikan lele di desa Parigi Mekar, Kec. Ciseeng , Kabupaten Bogor.

2. Mengetahui marjin pemasaran lembagalembaga perantara yang terlibat dalam tataniaga benih ikan lele serta fungsi pemasaran yang dilakukan oleh masingmasing lembaga perantara tersebut.

3. Mengetahui efisiensi rantai tataniaga yang dikaitkan dengan perbedaan harga serta penyebaran marjin pemasaran dari tiap lembaga perantara yang terlibat.

\section{METODE PENELITIAN}

\section{Waktu dan Tempat}


Penelitian ini dilakukan di desa Parigi Mekar, Kecamatan Ciseeng, Kabupaten Bogor, pada bulan Februari - Juni 2010.

Metodologi

Metode yang digunakan dalam penelitian ini adalah metode survey pada sentra produksi benih ikan lele yaitu desa Parigi Mekar. Untuk pengambilan data primer diperoleh dari hasil usaha bersama pembudidaya benih ikan lele, observasi lapang dan wawancara langsung dengan menggunakan kuesioner. Sedangkan data skunder diambil melalui data yang tersedia pada instansi terkait.

Analisis Data

Data primer dan skunder dianalisis untuk mengetahui kegiatan serta fungsi-fungsi pemasaran. Analisis pemaaran dalam penelitian ini dilakukan dengan cara menghitung marjin pemasaran dan penyebarannya pada setiap lembaga perantara yang terlibat pada system pemasaran yang dilakukan. Untuk menganalisa harga pokok, data yang dikumpulkan dari pembudidaya/responden dan petugas yang terkait, lalu diolah dan disajikan dalam bentuk tabulasi.

\section{Analisis Mata rantai Pemasaran}

Analisis mata rantai pemasaran dilakukan untuk mengetahui berbagai saluran tataniaga yang dilakukan dalam memasarkan benih ikan lele, mulai dari produsen sampai pada konsumen.

\section{Analisis Harga Pokok}

Harga pokok produksi dihitung berdasarkan besar-kecilnya biaya yang dikeluarkan dan hasil produk rielnya. Harga pokok produksi dihitung Harga pokok produksi $=\frac{\text { Biaya tetap total }+ \text { biaya variable total }}{\text { Jumlah produksi riel }}$

\section{Analisis Marjin Pemasaran}

Analisis marjin pemasaran digunakan untuk melihat tingkat efisiensi operasional pemasaran benih ikan lele, Marjin pemasaran dihitung berdasarkan pengurangan harga penjualan dengan harga pembelian pada setiap tingkat lembaga perantara. Untuk mengetahui berapa besar penerimaan yang akan diterima dari setiap rupiah yang dikeluarkan oleh masing-masing lembaga perantara dalam kegiatan pemasaran benih lele dumbo dapat dilihat dari ratio penerimaan terhadap biaya, perhitungannya dilakukan dengan rumus (Limbong dan Sitorus, 1987):

$$
\text { Msi }=\text { Psi }- \text { Pbi }
$$




$$
\mathrm{Msi}=\mathrm{Ci}+\mathrm{Bi}
$$

dimana;

Msi : marjin pemasaran pada tingkat i,

Psi : harga jual pada tingkat i,

Pbi : harga beli pada tingkat i,

Ci : biaya pemasaran pada tingkat $\mathrm{i}$,

$\mathrm{Bi}$ : keuntungan hasil pemasaran pada tingkat i,

Ratio terhadap biaya dapat digunakan untuk mengukur tingkat keuntungan relative dari kegiatan pemasaran benih ikan lele dumbo tersebut. Artinya dari angka rasio penerimaan terhadap biaya tersebut dapat diketahui apakah mata rantai pemasaran benih ikan lele dumbo dapat menguntungkan atau tidak. Suatu pola pemasaran dikatakanmenguntungkan jika nilai ratio lebih besar dari satu (1), dan mengalami kerugian jika nilai ratio lebih kecul dari satu (1). Untuk mengetahui berapa besar penerimaan yang akan didapat dari setiap rupiah yang dikeluarkan oleh masing-masing lembaga perantara dalam kegiatan pemasaran benih ikan lele dumbo dapat dilihat dari ratio penerimaan terhadap biaya, perhitungan dilakukan dengan rumus (Suharjo dan Patong, 1973): R/C ..............(3) dimana;

R (revenue) : pendapatan

C (cost) : pengeluaran/biaya

\section{HASIL DAN PEMBAHASAN}

Dari keseluruhan data/informasi yang diperoleh diharapkan adanya gambaran menyeluruh mengenai . mata rantai pemasaran benih ikan lele dari produsen sampai ke konsumen pemakai yang dilakukan oleh pembudidaya di desa/wilayah penelitian. Pada umumnya pembudidaya memasarkan ikannya sejak masih berada didalam kolam dan lama pemeliharaan sudah mencapai satu bulan. Hal ini didasarkan atas pertimbangan keselamatan dan kesehatan benih ikan tersebut tersebut, sehingga terjadi keseimbangan antara permintaan dan penawaran. Pembudidaya tidak takut menahan benih ikannya (produknya) karena semakin besar ukuran benih ikannya maka harga nya pun semakin tinggi. Mata rantai pemasaran utama yang dimaksud seperti tersebut diatas adalah yang jumlah pembelian atau penjualan relative lebih besar. Bili ditelusuri mata rantai pemasaran benih ikan lele dari awal yaitu dari pembudidaya maka pembelian atau penjualan dari masing-masing lembaga perantara tersebut adalah sebagai berikut: 
Mata rantai pemasaran 1.

Produsen (pembudidaya) $\longrightarrow$ Pedagang pengumpul desa Kecamatan $\longrightarrow$ Pedagang Pengecer Konsumen.

2. Mata rantai pemasaran 2.

Produsen (pembudidaya) $\longrightarrow$ Pedagang pengumpul Kecamatan $\longrightarrow$ Pedagang Pengecer $\longrightarrow$ Konsumen

Gambar 2. Mata rantai Pemasaran lele dumbo di Desa Parigi Mekar

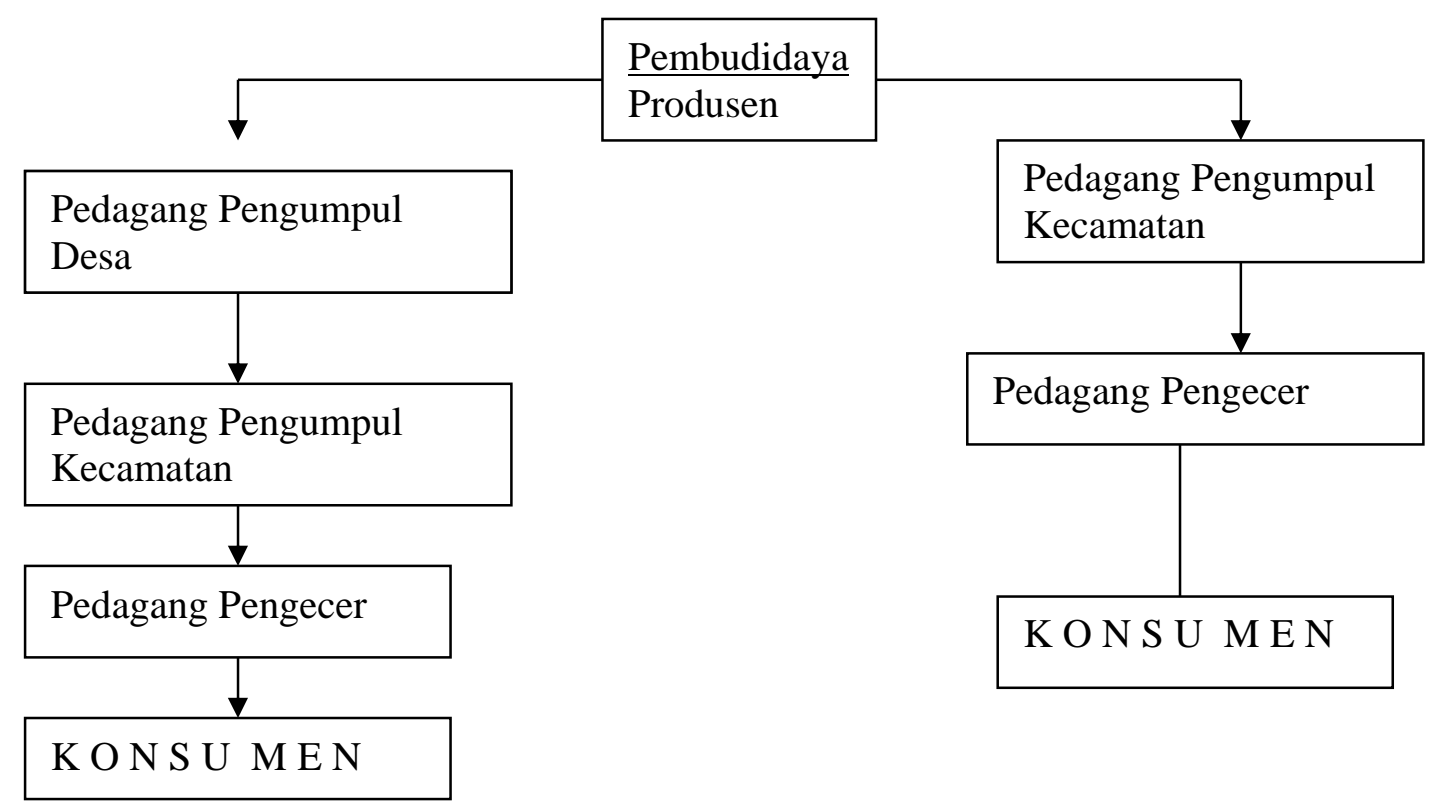

Gambar 1. Mata Rantai Pemasaran Benih ikan lele di Desa Parigi mekar, Kec. Ciseeng, Bogor. Keterangan :M.R.P. 1 . Pengumpul Kecamatan

M.R.P. 2. Pengecer pasar

Dari skema gambar diatas dapat dimiliki dan kepada pedagang pengumpul disimpulkan bahwa keragaman pemasaran kecamatan kalau pedagang pengumpul desa benih ikan lele yang dilakukan oleh tidak sanggup menampung kelebihan pembudidaya di desa Parigi Mekar terdapat dua produknya, dan sebagian lagi dipelihara sendiri mata rantai pemasaran yaitu; sebagai calon induk nantinya, atau dijual 1). Mata rantai pemasaran pertama (1), kepada pembesar diwilayah produksi tanpa penbudidaya menjual benih ikan lele kepada perantara, Sedangkan pedagang pengumpul pedagang pengumpul desa sebanyak yang desa menjual benih ikan lele kepada pedagang 
pengumpul kecamatan sesuai permintaan. produk tersebut dihasilkan dan siap untuk Pedagang pengumpul kecamatan menjual benih ikan lele yang dibeli dari pedagang pengumpul desa dan pembudidaya (produsen) kepada konsumen sesuai permintaan umumnya 100\% tanpa resiko penampungan.

2), Mata rantai pemasaran dua (2), alur pemaaran yang dilakukan hampir sama dengan mata rantai pemasaran satu (1), perbedaannya pedagang pengumpul kecamatan langsung membeli ke pembudidaya lele (produsen) tanpa melalui pedagang pengumpul desa, biasanya pesanan sesuai yang diinginkan dan ukuran sesuai permintaan konsumen, hal ini dimaksud untuk mendapatkan benih ikan lele yang baik dan mendapaykan harga yang relatif rendah, serta mendapatkan keuntungan yang lebih besar.

\section{Analisis Harga Pokok}

Harga pokok merupakaninput total atau jumlah seluruh pengeluaran yang digunakan untuk proses produksi hingga menghasilkan suatu produk dalam kondisi dan tempat dimana

Tabel.1. Komponen Biaya pada Usaha Budidaya benih ikan lele di Desa Parigi mekar saat penelitian antara bulan Februari - Juni 2010. per 300 m persegi

\begin{tabular}{|l|l|l|r|r|}
\hline NO & Jenis Biaya & Harga /unit/Rp & Biaya (Rp) & Total (Rp) \\
\hline 1. & Biaya variable & & & \\
& -Benih lele (2-3)cm (60.0000 ek) & 15 & 900.000 & \\
& -Pupuk; Urea 5 kg & 1200 & 6.000 & \\
& Tsp 5 kg & 1800 & 9.000 & \\
& Kotoran ayam/postal 150 kg & 750 & 112.500 & \\
\hline
\end{tabular}




\begin{tabular}{|c|c|c|c|c|}
\hline 2. & $\begin{array}{l}\text { Pakan ikan } 30 \text { kg } \\
\text { Obat-obatan } 1 \text { paket } \\
\text { Upah t. k. lepas } 2 \text { hari } \\
\text { T. k. Pembudidaya } 1 \text { bulan } \\
\text { Bunga modal } 12 \% / \text { tahun } \\
\quad \text { Jumlah } \\
\text { Biaya Tetap; } \\
\text { Sewa lahan } 300 \text { m,. } 1 \text { bulan } \\
\text { Penyusutan alat } 1 \text { bulan } \\
\text { Bunga modal } \\
\quad \text { Jumlah } \\
\text { Total Biaya (1 + 2) } \\
\text { Produklsi riel } 45.000 \text { ekor }(5-6) \mathrm{cm}\end{array}$ & $\begin{array}{l}11.000 \\
50.000 \\
35.000 \\
100.000\end{array}$ & $\begin{array}{r}330.000 \\
50.000 \\
70.000 \\
100.000 \\
189.300\end{array}$ & $\begin{array}{l}\frac{145.600}{1.912 .400} \\
3.150 .000\end{array}$ \\
\hline
\end{tabular}

Diolah : Juni 2010

Untuk menghitung harga pokok per ekor benih ikan lele, maka dengan rumus (Hanafiah, 1986)

Harga Pokok Biaya variable + biaya tetap

Jumlah produksi riel

Berdasarkan perhitungan dari table tersebut maka harga pokok dari usaha benih ikan lele di Desa Parigi Mekar pada saat penelitian adalah sebagai berikut;

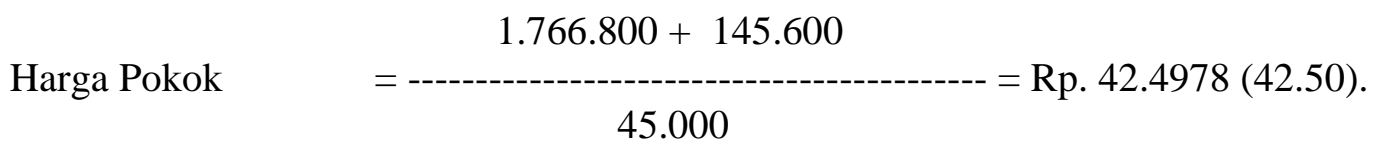

Pada saat penelitian pembudidaya menjual benih ikan lele ukuran (5-6) cm kepada pedagang pengumpul desa maupun pedagang pengumpul kecamatan, seharga Rp. 70,-/ekor. Keuntungan yang diperoleh pembudidaya saat penelitian sebesar ; Rp. 70,- Rp 42.50,- = Rp 27.50,-.

\section{Analisis Penyebaran Marjin Pemasaran}

Penelitian dipusatkan pada produsen yang menjual benih ikan lele kepada pedagang perantara, sedangkan marjin pemasaran yang dianalisis yaitu antara lembaga perantara yang terlibat langsung sesuai dengan mata rantai pemasaran yang ditempuh/dilakukan di desa Parigi Mekar. Untuk lebih jelasnya dapat dilihat pada table berikut; 
Tabel.2 . Marjin Pemasaran Benih Ikan Lele di desa Parigi Mekar

\begin{tabular}{|c|c|c|c|c|c|}
\hline $\mathrm{NO}$ & Uraian & \multicolumn{2}{|c|}{ Mata rantai 1} & \multicolumn{2}{|c|}{ Mata Rantai 2} \\
\hline & & Rp/ekor & $\%$ & Rp/ekor & $\%$ \\
\hline \multirow{4}{*}{1.} & Produsen & 70 & - & 70 & \\
\hline & -Harga Pokok & 42.50 & - & 42.50 & \\
\hline & -biaya Pemasaran & & - & & \\
\hline & -Keuntungan & 27.50 & - & 27.50 & \\
\hline \multirow[t]{5}{*}{2.} & Ped. Peng. Desa & & & & \\
\hline & -Harga beli & 70 & 77.80 & - & \\
\hline & -Marjin Pemasaran & 20 & 22.20 & - & \\
\hline & -Biaya Pemasaram & 5 & 5.60 & - & \\
\hline & -Keuntungan & 15 & 16.40 & - & \\
\hline \multirow[t]{5}{*}{3.} & Ped. Peng. Kecamatan & & & & \\
\hline & -Harga beli & 90 & 81.20 & 70 & 63.64 \\
\hline & -Marjin Pemasaran & 20 & 18.80 & 40 & 36.36 \\
\hline & -Biaya Pemasaram & 7.5 & 6.82 & 10 & 9.09 \\
\hline & -Keuntungan & 12.5 & 11.98 & 30 & 27.27 \\
\hline \multirow[t]{5}{*}{4.} & Ped. Pengecer & & & & \\
\hline & -Harga beli & 110 & 88.00 & 110 & 88.00 \\
\hline & -Marjin Pemasaran & 15 & 12.00 & 15 & 12.00 \\
\hline & -Biaya Pemasaram & 2.5 & 2.00 & 2.5 & 2.00 \\
\hline & -Keuntungan & 12.5 & 10.00 & 12.5 & 10.00 \\
\hline \multirow[t]{2}{*}{5} & Konsumen & & & & \\
\hline & -Harga beli & 125 & - & 125 & \\
\hline
\end{tabular}

Keterangan ; mata rantai 1 : pengecer/pasar Mata rantai 2 : pengecer khusus

Diolah : Juni 2010

\section{Analisi Marjin Pemasaran}

Total marjin pemasaran pada mata rantai pemasaran 1, yaitu Rp. 55/ekor yang mempunyai selisih dari harga jual produsen dengan harga yang dibayar oleh konsumen sekitar $44 \%$, itu teralokasikan untuk biaya pemasaran Rp. 15/ekor, atau $12 \%$, dan keuntungan sebesar Rp. 40/ekor atau $32 \%$. Untuk mata rantai pemasaran 1, maka presentase tertinggi diperoleh pedagang pengumpul desa sebesar Rp 20/ekor atau 22.20
\%, karena melakukan penanganan yang lama dan panjang, sedangkan pedagang pengumpul kecamatan sebesar Rp. 20,-/ekor atau $18.20 \%$. Sedang biaya pemasaran tertinggi dikeluarkan oleh pedagang pengumpul kecamatan sebesar Rp. 7.5,-/ekor atau $6.82 \%$ dan pedagang pengumpul desa sebesar Rp. 5,-/ekor atau 5.6\%. Hal ini menunjukkan kuatnya pendekatan pedagang pengumpul desa dan kecamatan. Karena lembaga perantara yang terkait aktif secara langsung melakukan 
pembelian dari produsen (pembudidya) dan menjual kembali kepada pengecer/pasar atau konsumen diluat wilayah produksi.

Pola mata rantai pemasaran dua (2), yang dilakukan oleh produsen di desa Parigi Mekar besarnya marjin pemasaran adalah Rp. 55,/ekor atau $44 \%$. Dari data tersebut persentase keuntungan terbesar diperoleh pedagang pengumpul kecamatan sebesar Rp. 30,-/ekor atau $27.27 \%$ dan lebih tinggi bila dibandingkan dengan pedagang pengumpul desa pada mata rantai pemasaran satu (1), perbedaan tersebut karena disebabkan pedagang pengumpul kecamatan membeli langsung kepada produsen tanpa perantara dengan harga yang sama dengan produsen menjual kepada pedagang pengumpul desa, sehungga perbedaan marjin pemasaran pada mata rantai satu dan mata rantai pemasaran dua sebesar $4.04 \%$

Perbedaan biaya pemaaran antara mata rantai satu dan mata rantai pemasaran dua sebesar Rp.2.5,- atau 2.0\%, dan keuntungan yang diperoleh lembaga pemasaran yang terlibat pada mata rantai satu sebesar $32 \%$ dan mata rantai pemasaran dua sebesar $34 \%$. Untuk lebih jelas dapat dilihat pada table berikut.
Apabila dilihat dari perbedaan harga yang diterima produsen dan harga yang dibayar oleh konsumen alur pada mata rantai satu dengan mata rantai pemasaran dua tidak terdapat perbedaan dimana mata rantai satu marjin pemasaran sebesar Rp.55,-/ekor sama dengan mata rantai pemasaran dua.

Bila diperhitungkan rasio penerimaan terhadap biaya pemasaran dari masing-masing lembaga perantara untuk setiap saluran pemasaran (satu dan dua), maka R/C ratio benih ikan lele mulai dari produsen sampai pedagang pengecer dapat dilihat pada table berikut;

Tabel. 3. . Rasio Penerimaam\n Terhadap Biaya pada Saluran Pemasaran di desa Parigi Mekar

\begin{tabular}{|c|c|c|c|}
\hline NO & Uraian & Saluran 1 & Saluran 2 \\
\hline 1. & $\begin{array}{l}\text { Pedagang pengumpul Desa } \\
\text { - Biaya pemasaran } \\
\text { - Penerimaan }\end{array}$ & $\begin{array}{l}\text { Rp. } 5,00 \\
\text { Rp. } 20,00\end{array}$ & \\
\hline
\end{tabular}




\begin{tabular}{|l|l|l|l|}
\hline 2. & - R/C rasio & 4 & \\
& Pedagang Pengumpul Kecamatan & & \\
& - Biaya pemasaran & Rp. 7.5,00 & Rp. 10,00 \\
- Penerimaan & Rp. 20,00 & Rp. 10,00 \\
3, & 2.67 & 3 \\
- R/C rasio & & \\
Pedagang Pengecer & Rp. 2.5,00 & Rp. 2.5,00 \\
& - Biaya pemasaran & Rp. 15,00 & Rp. 15,00 \\
& - Penerimaan & 6 & 6 \\
\hline
\end{tabular}

Diolah : Juni 2010

Dari table diatas rasio penerimaan terhadap biaya untuk saluran pemasaran satu tertinggi diperoleh pedagang pengecer sebesar 6, begitu pula pada saluran pemasaran dua diperoleh pedagang pengecer sebesar 6 .

\section{KESIMPULAN DAN SARAN}

\section{Kesimpulan}

Konsumen pengguna benih lele ini terutama adalah pembudidaya ikan konsumsi, mereka membeli benih ikan lele untuk dipelihara dengan tujuan menghasilkan ikan konsumsi.

Saluran pemasaran yang ditempuh oleh pembudidaya (produsen) di desa penelitian terdiri dari dua saluran pemasaran yaitu;

1. Produsen $\longrightarrow$ Pedagang Pengumpul Desa

$\longrightarrow$ Pedagang Pengumpul Kecamatan

Pedagang Pengecer Konsumen.

2. Produsen $\longrightarrow$ Pedagang Pengumpul Kecamatan $\longrightarrow$ Pedagang Pengecer $\longrightarrow$ Konsumen.

Masing-masing lembaga perantara dibandingkan saluran satu, karena penangnan malakukan kegiatan dari fungsi pemasaran (handling) yang sedikit dan pendeknya saluran yang secara umum yaitu; 1), fungsi pertukaran, pemasaran.

2).fungsi fasilitas dan 3). fungsi fisik.

Marjin pemasaran pada mata rantai

Dilihat dari harga yang dibayar oleh pemasaran satu (1) persentase tertinggi konsumen saluran satu maupun saluran dua dipetoleh pedagang pengumpul desa sebesar tidak berbeda, tetapi dari mutu benih yang Rp. 20,00 atau $22.20 \%$, dan pada mata rantai diterima konsumen, saluran dua lebih baik pemasaran dua (2) persentase tertinggi 
dipetoleh pedagang pengumpul kecamatan sebesar Rp. 30,00 atau $27.27 \%$,

Bila dilihat dari pemberdayaan ekonomi masyarakat pedesaan, maka mata rantai pemasaran satu (1) sangat mendukung terciptanyan perekonomian pedesaan dan menciptakan lapangan kerja disektor perdagangan di pedesaan.

Memberikan pegangan bagi penyuluh untuk menyampaikan teknologi budidaya ikan lele dumbo kepada sasaran ditinjau dari segi manajemen usaha yang telah diteliti, sehingga memberikan motivasi kepada pembudidaya untuk memperbaiki teknologi dan meningkatkan produksi.

\section{Saran}

Agar efisien sistem pemasaran benih ikan lele di Desa Parigi Mekar, maka perlu dibentuk kelompok pembudidaya ikan yang berfungsi sebagai pusat pasar benih ikan, agar dapat mengorganisir pembudidaya ikan dan dapat menjual benih langsung pada pedagang pengumpul kecamatan tentunya dengan harga yang lebih baik, sehingga tidak terjadi rantai pemasaran yang terlalu panjang.

Untuk memafaatkan saluaran dua agar resiko kematian benih dapat diperkecil maka perlu dibentuk suatu badan (koperasi) yang berfungsi sebagai pusat penjualan benih ikan.

\section{DAFTAR PUSTAKA}

Abbott,J.C, 1958. Marketing Problem an Improvement Program, FAO Marketing Guide No 1. Rome.

Brunk,M.E \& L.B.Darrah,1955. Marketing of Agriculture Product. The Ronald press Company, New York.

Downwey,D.\&Steven,P.E,1986. Manajemen Agribisnis, Erlangga Jakarta.

Hague,P.\& Peter,J.1993. Riset Pemasaran dalam Praktik, Pustaka Presindo, Jakarta.

Hanafiah,A.M \& Saefuddin, 1986. Tataniaga Hasil Perikanan. Universitas Indonesia Press, Jakarta

Kotler P,1987. Dasar-dasar Pemasaran. PT. Mides Surya Grafindo, Jakarta.

Limbong,W.H.\& Sitorus 1987. Pengantar Tataniaga Pertanian. Institut Pertanian Bogor Press. Bogor

Prawirokusumo,S.1990. Ilmu Usahatani. BPPE, Yogyakarta.

Winardi.1980. Azas-azas Marketing. Alumni Bandung. 